\title{
Proceeding
}

Supplementary Issue: Winter Conferences of Sports Science. Costa Blanca Sports Science Events, 22-23 March 2021. Alicante, Spain.

\section{Biomechanical analysis of the late approach and the take off in the indoor women's long jump}

\author{
VASSILIOS PANOUTSAKOPOULOS ${ }^{1}$, APOSTOLOS S. THEODOROU², EFSTRATIOS FRAGKOULIS ${ }^{3}$, \\ MARIANA C. KOTZAMANIDOU 4 \\ ${ }^{1}$ Biomechanics Laboratory, Department of Physical Education and Sports Sciences at Thessaloniki, Aristotle University \\ of Thessaloniki, Thessaloniki, Greece \\ ${ }^{2}$ School of Physical Education and Sports Sciences, National and Kapodistrian University of Athens, Athens, Greece \\ ${ }^{3}$ School of Physical Education and Sports Sciences, Democritus University of Thrace, Komotini, Greece \\ ${ }^{4}$ Faculty of Health Sciences, Metropolitan College of Thessaloniki, Thessaloniki, Greece
}

\begin{abstract}
Aim of the study was to provide evidence concerning the biomechanical parameters of contemporary Women's long jump in indoor competition. The final six steps and the take-off of 11 jumps ( $6.88 \pm 0.23 \mathrm{~m}$ ) were recorded (panning camera; sampling frequency: $300 \mathrm{fps}$ ) in an indoor competition. The examined parameters were a) the step parameters, the percentage distribution of adjustment (ADJ\%) and the inter-limb symmetry angle $\left(\theta_{\text {sym }}\right)$ in the late approach, $b)$ the joint angles and the take-off parameters. Pearson's correlation analysis revealed that approach velocity $(9.8 \pm 0.3 \mathrm{~m} / \mathrm{s})$ was significantly correlated $(r=.86, p=.001)$ with effective distance $(6.96 \pm$ $0.23 \mathrm{~m}$ ). The largest ADJ\% (57.6 \%) was executed at the penultimate step which was $12.2 \pm 2.8 \%$ larger than the last step. An inter-limb difference was revealed for step frequency $\left(t_{10}=6.965, p<.001\right)$ due to the large asymmetry observed $\left(\theta_{\text {SYM }}=5.54 \mathrm{deg}\right)$. The knee angle of the push-off leg at take-off was $171.2 \pm 4.7 \mathrm{deg}$. Resultant velocity $(8.3 \pm 0.4 \mathrm{~m} / \mathrm{s})$, height $(1.15 \pm 0.05 \mathrm{~m})$ and angle $(20.7 \pm 2.3 \mathrm{deg})$ of take-off significantly predicted effective distance $\left(F_{3,7}=12.671, p=.003, R^{2}=.844\right)$. The present findings are in reasonable agreement with previous research. Future studies should examine the possible reliance and asymmetry for the step parameters in the final approach.

Keywords: Track and Field; Asymmetry; Sports performance; Female; Speed; Take-off parameters.

Cite this article as:

Panoutsakopoulos, V., Theodorou, A.S., Fragkoulis, E., \& Kotzamanidou, M.C. (2021). Biomechanical analysis of the late approach and the take off in the indoor women's long jump. Journal of Human Sport and Exercise, 16(3proc), S1280S1292. https://doi.org/10.14198/jhse.2021.16.Proc3.44

Corresponding author. Biomechanics Laboratory, Department of Physical Education and Sports Sciences at Thessaloniki, Aristotle University of Thessaloniki, 54124 Thessaloniki, Greece. http://orcid.org/0000-0002-9832-0314

E-mail: bpanouts@phed.auth.gr

Abstract submitted to: Winter Conferences of Sports Science. Costa Blanca Sports Science Events, 22-23 March 2021. Alicante, Spain.

JOURNAL OF HUMAN SPORT \& EXERCISE ISSN 1988-5202.

(c) Faculty of Education. University of Alicante.

doi:10.14198/jhse.2021.16.Proc3.44
\end{abstract}

S1280 | 2021| Proc3| VOLUME 16

(c) 2021 University of Alicante 


\section{INTRODUCTION}

The current knowledge about the long jump is acquired from biomechanical analyses conducted in major international competitions (Arampatzis and Brüggemann, 1999; Mendoza and Nixdorf, 2011; Panoutsakopoulos et al., 2017; Tucker et al., 2018). The relationship among those parameters and long jump performance is mainly examined with correlation analysis (Hay and Miller, 1985; Luhtanen and Komi, 1979), regression analysis (Graham-Smith and Lees, 2005; Letzelter, 2011; Nemtsev et al., 2018) and factor analysis (i.e., Principal Components Analysis, Campos et al., 2013b; Panoutsakopoulos et al., 2007). Based on these analyses, the attained speed during the approach and, corollary, the take-off velocity are considered as determinant factors for the jumping distance (Hay, 1993).

The values of parameters identifying the technique elements at take-off (i.e., knee extension angle) are suggested to be similar between men and women (Linthorne, 2008; Panoutsakopoulos and Kollias, 2009). On the opposite, female long jumpers were found to perform with lower take-off velocities compared to males (Akl, 2014; Hay and Miller, 1985; Nemtsev et al., 2016; Panoutsakopoulos et al., 2017). Another gender difference is the fact that female long jumpers rely primarily on a higher vertical take-off velocity rather than attaining a higher horizontal take-off velocity (Letzelter, 2011). This can be due to the fact that, unlike men, a net loss of energy was evident during the push-off in women (Lees et al., 1992).

Gender differences also appear in the approach run. Higher velocity is attained by men who did not significantly modify the step parameters among the 3rd- to-last and penultimate step (Panoutsakopoulos et al., 2017) but not for the women. According to the same study, the rhythmic execution of the penultimate step is the decisive factor for the gender differences in the long jump. As for the last step, its length, the torso inclination and the joint angular kinematics were different when male and female jumpers of the same performance level were compared (Murakami and Takahashi, 2016).

To attain the maximum controlled speed that is the requirement for optimizing the take-off, the approach run should be executed with a consistent step length and speed development pattern (Hay, 1986). However, due to a considerable variance in toe-to-board distance for a given step during the early approach run (Theodorou et al., 2017), jumpers of both genders regulate their step length in the last five steps (Hay, 1988). It has been reported that sub-elite female athletes showed significant inter-limb asymmetry in step length in the late approach (Exell et al., 2016). A resent research also demonstrated lateral differences in the temporal parameters of the last steps in an elite athlete (Panoutsakopoulos et al., 2020).

Research evidence in female long jumping is limited due to the small number of publications and sample size of the examined high level jumpers (Letzelter, 2011). In addition, considerably less research is conducted concerning the women's indoor long jump in competition (Campos et al., 2013a; Nemtsev et al. 2016; Tucker et al., 2019). Thus, the aim of the present study was to examine the biomechanical parameters and their relationship with performance in the contemporary elite female indoor long jumping. The focus of this study was to provide updated information in the literature regarding the inter-limb differences in the final approach and the contribution of the take-off parameters in the jumping distance.

\section{MATERIAL AND METHODS}

\section{Participants}

Eleven jumps ( $6.88 \pm 0.23 \mathrm{~m}$ ) performed by four finalists (age: $27.2 \pm 1.7 \mathrm{yrs}$;; height: $1.78 \pm 0.03 \mathrm{~m}$; mass: $60.8 \pm 4.0 \mathrm{~kg}$ ) of the Women's Long Jump event in the 2017 European Athletics Indoor Championships held 
in Belgrade, Serbia (05/03/2017) were examined. The study was conducted after obtaining the permission of the European Athletics Association. The experimental procedures were in line to the Declaration of Helsinki. The Institutional Research Committee provided ethical approval (approval no.: 14973/2017).

\section{Data acquisition}

The jumps were recorded with a high speed video camera (Casio EX F1; Casio Computer Co. Ltd., Shibuya, Japan) operating at a sampling frequency of $300 \mathrm{fps}$ and the settings proposed by Pueo (2016). The camera was positioned on a fixed tripod. The placement of the camera was in the stands, at a distance of $30 \mathrm{~m}$ from the approach runway and about $2 \mathrm{~m}$ prior the take-off board. Pairs of $0.05 \mathrm{~m} \times 0.05 \mathrm{~m}$ custom reference markers were placed on both sides of the approach runway. The camera was manually panned. The field of view was zoomed to capture both the jumper and the markers along the runway. Recording included the last six steps of the approach, the take-off from the board, the flight and the landing. The conduction of the panning analysis was consistent with the recommendations of Gervais et al. (1989).

\section{Data analysis}

Step parameters: The step parameters were extracted using the APAS WIZARD 14.1.0.5 software (Ariel Dynamics Inc., Trabuco Canyon, CA, USA). Toe-to-board distance (TBD) was calculated by projecting the point of the athlete's toe at touchdown onto a line between pairs of markers. The real ("effective") jumping distance ( $\mathrm{S}_{\mathrm{EFF}}$ ) was the official distance added the TBD of the take-off step. Step length (SL) was the TBD difference between two consecutive steps. Contact (TC) and flight (TFL) times, as well as the TFL to TC ratio (TRATIO) were measured for each step. In addition, step frequency (SF) and average approach velocity (ASVAPP) were calculated as shown in equations 1 and 2 :

$$
\begin{gathered}
S F=\frac{1}{(T C+T F L)} \\
A S V_{A P P}=\frac{S L_{3}+S L_{2}+S L_{1}}{\left(T C_{3}+T F L_{3}\right)+\left(T C_{2}+T F L_{2}\right)+\left(T C_{1}+T F L_{1}\right)}
\end{gathered}
$$

where 1, 2, 3 are the last, penultimate and 3rd to last step prior the take-off, respectively.

An inter-trial analysis that accounts the standard deviation of TBD (TBD $\mathrm{SD}$ ) for a set amount of step across all the examined jumper's attempts was utilized for the estimation of the adjustment of SL, as this is considered to reflect the regulatory action for an accurate foot placement on the board (Hay, 1988). According to this method, the percentage distribution of adjustment (ADJ\%) was extracted for each examined step as displayed in equation 3:

$$
A D J_{\%}=\frac{\left(T B D_{S D i}-T B D_{S D i-1}\right)}{\left(T B D_{S D \max }-T B D_{S D 0}\right)} \times 100
$$

where $i$ is the ith-last contact, TBDsDmax is the maximum TBDSD value observed and TBDsDo is the TBDsD at the board. 
Inter-limb asymmetry: Inter-limb asymmetry was quantified for SL and SF between the mean values for the take-off (TOL) and swing (SWL) leg steps for each jumper based on symmetry angle ( $\theta$ sym, Exell et al., 2016), as presented in equation 4 :

$$
\vartheta_{S Y M}=\frac{\left(45^{\circ}-\arctan \left(\frac{x S W L}{x T O L}\right)\right)}{90^{\circ}} \times 100 \%
$$

where $\theta$ sym is the symmetry angle, $x S W L$ is the mean value for the SWL steps and $x T O L$ is the mean value for the TOL steps. However, if

$$
\left(45^{\circ}-\arctan \left(\frac{x S W L}{x T O L}\right)\right)>90^{\circ}
$$

then equation 4 was changed to equation 5 :

$$
\vartheta_{S Y M}=\frac{\left(45^{\circ}-\arctan \left(\frac{x S W L}{x T O L}\right)-180^{\circ}\right)}{90^{\circ}} \times 100 \%
$$

\begin{tabular}{|c|c|}
\hline Parameter & Definition \\
\hline BCM horizontal velocity $\left(\mathrm{V}_{\mathrm{x}} \mathrm{)}\right)$ & horizontal velocity of BCM at the instant of take-off \\
\hline $\mathrm{BCM}$ horizontal velocity loss $\left(\Delta \mathrm{V}_{\mathrm{x}}\right)$ & $\begin{array}{l}\text { BCM horizontal velocity loss at the instant of take-off } \\
\text { compared to the instant of touch-down on the board }\end{array}$ \\
\hline BCM vertical velocity ( $\left.\mathrm{Vy}_{0}\right)$ & vertical velocity of BCM at the instant of take-off \\
\hline Take-off velocity ratio ( $\left.V_{\text {RATIO }}\right)$ & Ratio of $\mathrm{V}_{\mathrm{o}} / \mathrm{V}_{\mathrm{o}}$ \\
\hline Resultant BCM take-off velocity $\left(\mathrm{V}_{0}\right)$ & resultant velocity of BCM at the instant of take-off \\
\hline BCM take-off height $\left(h_{0}\right)$ & height of BCM at the instant of take-off \\
\hline Take-off angle $\left(\theta_{0}\right)$ & arc -tangent of $\mathrm{V}_{\mathrm{y}} / \mathrm{V}_{0}$ at the instant of take-off \\
\hline Effective take-off distance (DEFF) & $\begin{array}{l}\text { horizontal distance from the BCM to the toe of the take-off leg } \\
\text { at the instant of take-off } \\
\text { the angle formed in the sagittal plane by the horizontal axis }\end{array}$ \\
\hline Leg placement angle ( $\varphi$ LTD) & $\begin{array}{l}\text { and the line passing the hip and the ankle joint of the take-off } \\
\text { leg at the instant of touchdown on the board }\end{array}$ \\
\hline Knee angle at touchdown ( $\theta$ kTD) & $\begin{array}{l}\text { angle between the shin and the thigh of the take-off leg at the } \\
\text { instant of touchdown }\end{array}$ \\
\hline Knee angle at take-off $\left(\theta k_{0}\right)$ & $\begin{array}{l}\text { angle between the shin and the thigh of the take-off leg at the } \\
\text { instant of take-off }\end{array}$ \\
\hline $\begin{array}{l}\text { Angle of the knee of the swing leg at take- } \\
\text { off }\left(\theta k s w_{0}\right)\end{array}$ & $\begin{array}{l}\text { angle between the thigh and the shank of the swing leg at the } \\
\text { instant of take-off. }\end{array}$ \\
\hline
\end{tabular}

Table 1. Definitions of the kinematic take-off parameters examined in the study. 
Take-off kinematical parameters: The K-Motion (Kinvent Biomecanique, Orsay, France) software was used for the kinematical analysis of the take-off. In each recorded field, twenty-two anatomical points of the body (top of the head, neck, shoulder, elbow, wrist, tip of the fingers, hip, knee, ankle, heel, metatarsals, tip of the toe, on both sides of the body) were manually digitized. The coordinates of the body centre of mass (BCM) were calculated as suggested by Dempster (1955). A second-order low-pass Butterworth filter (cut-off frequency: $10 \mathrm{~Hz}$ ) was selected for smoothing of the raw data. The accuracy of the 2D reconstruction was determined by Root Mean Square error. An error of $0.007 \mathrm{~m}$ and $0.005 \mathrm{~m}$ was found for the horizontal and vertical axis, respectively. The kinematical parameters examined are defined in Table 1.

\section{Statistical analysis}

Data are presented as mean \pm standard deviation (SD). Normality of distribution and the equality of variance were assessed using the Shapiro-Wilk test $(p>.05)$ and the Levene's test $(p>.05)$, respectively. Based on the results of these tests, parametrical statistical analyses were applied on the data. Paired samples T-test were used for the comparison of inter-limb differences concerning the step parameters. The effect sizes were evaluated using Cohen's $d$ (values of $<.2,<.5,<.8$ and $\geq .8$ were interpreted as trivial, small, medium and large effect size, respectively). Repeated measures ANOVA with Bonferroni adjustments were run to test the progression of step parameters from the 6th-to-last to the final step. Effect sizes were estimated using the partial eta-squared statistic $\left(\eta p^{2}\right)$. Values of $>.01,>.06$ and $>.14$ were considered as small, medium and large, respectively (Cohen, 1988). The relationship of the examined parameters with SEFF was checked using Pearson's correlation analysis. Finally, a multiple regression analysis (enter method) was used to examine if the take-off parameters could predict SEFF. The IBM SPSS Statistics v.25 software (International BusinesS Machines Corp., Armonk, NY) was used to run the statistical analysis. The level of significance was set at a $=.05$.

\section{RESULTS}

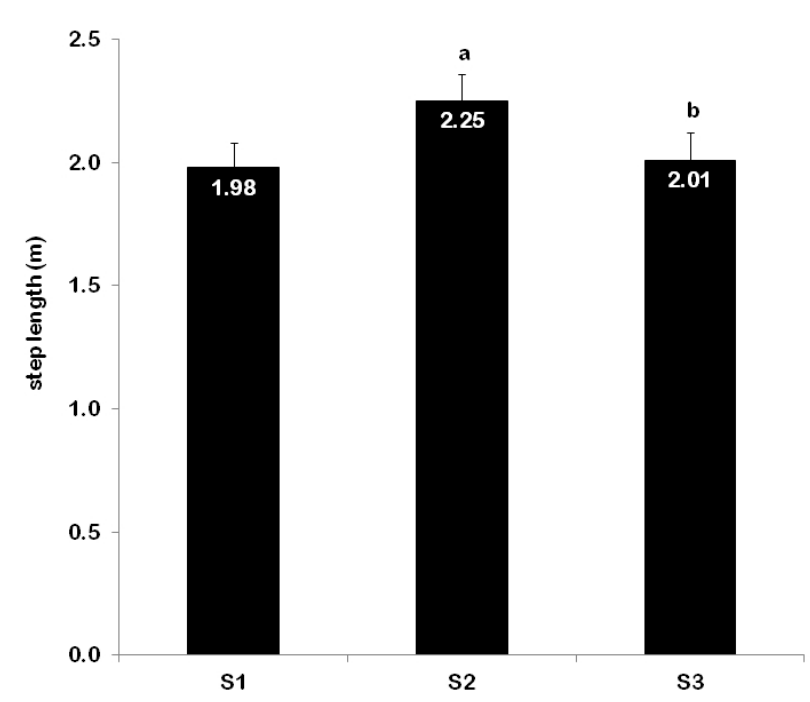

Note: S1, S2, S3 = last, penultimate and 3rd to last step prior the take-off, respectively; a: $p<.05$ vs. $1 S ; b: p<.05$ vs. $2 S$.

Figure 1. Average $(n=11)$ step length $(S L)$ at the three steps of the approach.

Approach step parameters: TBD of the foot placement on the board was $0.045 \pm 0.040 \mathrm{~m}$. ASV APP $(9.3 \pm 0.3$ $\mathrm{m} / \mathrm{s})$ was significantly correlated $\left(\mathrm{r}_{10}=.86, \mathrm{p}=.001\right)$ with $\mathrm{S}_{\mathrm{EFF}}(6.96 \pm 0.23 \mathrm{~m})$. A "larger penultimate - shorter last step" technique was evident in all the examined trials (Figure 1). In average, SL2 was $12.4 \pm 7.9 \%$ larger 
than SL3 and SL1 was $12.2 \pm 2.8 \%$ shorter than SL2 $\left(F_{5,35}=7499.479, p<.001, \eta p^{2}=.999\right)$. TBDsD was progressively reduced during the last three steps of the approach $(0.24 \mathrm{~m}, 0.19 \mathrm{~m}$ and $0.10 \mathrm{~m}$ for the thirdto-last, penultimate and last step, respectively). ADJ\% of the final three steps was $15.6 \%, 57.6 \%$ and $17.7 \%$ for the third-to-last, penultimate and last step, respectively.

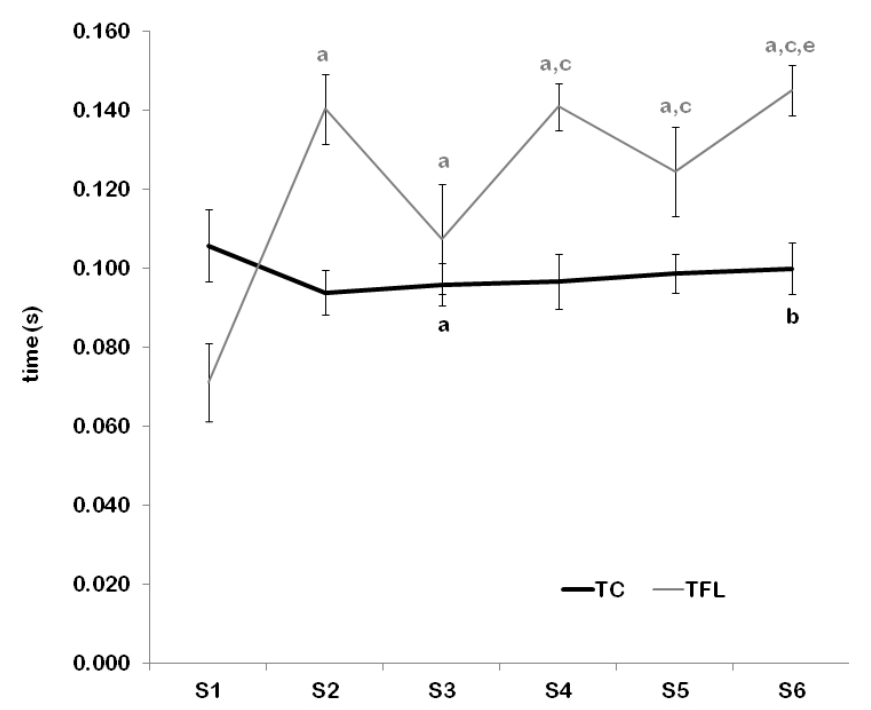

Note: S1, S2, S3, S4, S5, S6 = last, penultimate, 3rd,4th, 5th and 6th to last step prior the take-off, respectively; a: $p<.05$ vs. S1; $b: p<.05$ vs. S2; c: $p<.05$ vs. S3; e: $p<.05$ vs. S5.

Figure 2. Average $(n=11)$ contact $(T C)$ and flight $(T F L)$ time at the last six steps of the approach.

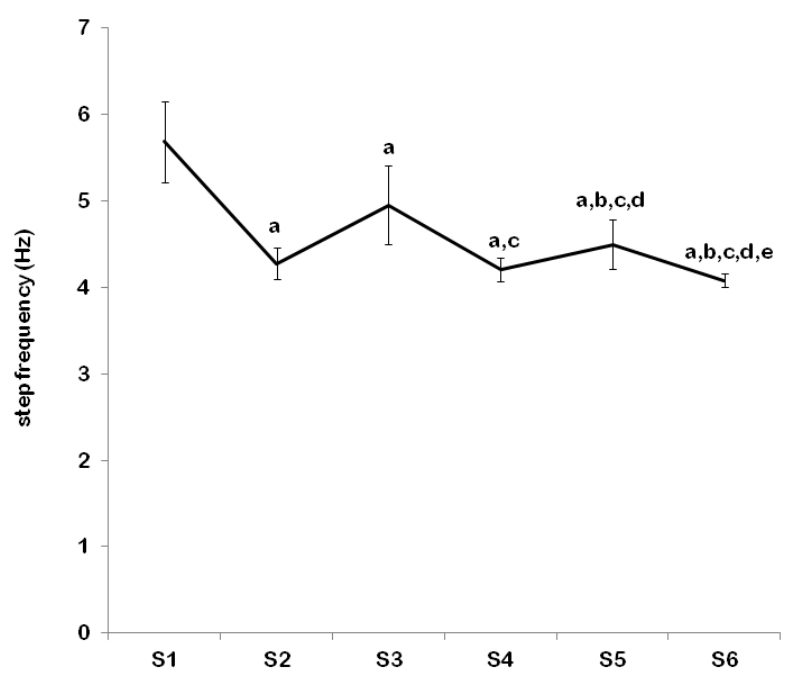

Note: S1, S2, S3, S4, S5, S6 = last, penultimate, 3rd,4th, 5th and 6th to last step prior the take-off, respectively; a: $p<.05$ vs. S1; $b: p<.05$ vs. S2; $c: p<.05$ vs. S3; e: $p<.05$ vs. S5.

Figure 3. Average $(n=11)$ step frequency $(S F)$ at the last six steps of the approach.

The final six steps were executed with an almost similar TC of approximately $0.1 \mathrm{~s}(0.098 \pm 0.007 \mathrm{~s})$. However, as in SL, significant large effect differences $\left(F_{5,35}=2357.623, p<.001, \eta p^{2}=.997\right)$ were observed for the last two steps compared to previous steps (Figure 2). On the contrary, TFL was fluctuating, with the 
TFL for the last step being the fastest of all $\left(F_{5,35}=4782.162, p<.001, \eta p^{2}=.999\right)$. It was also observed that the steps commenced from TOL had a longer TFL than the steps from SWL $\left(t_{10}=11.944, p<.001, d=3.6\right)$. The same fluctuating trend was also observed for $T_{\text {RATIO }}\left(F_{5,35}=2159.580, p<.001, \eta p^{2}=.997\right)$. The highest TRATIO was revealed for the penultimate step $(1.51 \pm 0.16)$.

SF during the final six steps was progressively increased $\left(F_{5,35}=4340.747, p<.001, \eta p^{2}=.998\right)$ up to the 4th to last step (Figure 3). The highest SF was recorded at the last step $(5.81 \pm 0.46 \mathrm{~Hz})$.

Inter-limb asymmetry: A closer examination of Figure 3 reveals that SF was altering with respect to TOL and SWL. Significant inter-limb asymmetry $\left(\theta_{\text {SYM }}=5.5 \pm 2.5 \mathrm{deg}\right)$ was revealed for $\mathrm{SF}(4.19 \pm 0.11 \mathrm{~Hz}$ and 5.01 $\pm 0.38 \mathrm{~Hz}$ for $x T O L$ and $x S W L$, respectively; $\left.t_{10}=6.965, p<.001, d=2.1\right)$. On the opposite, no significant ( $p$ $>.05)$ inter-limb asymmetry was evident for $\mathrm{SL}\left(\theta_{\mathrm{SYM}}=2.6 \pm 2.2 \mathrm{deg}\right)$.

Take-off kinematical parameters: The results of the take-off parameters are presented in Table 3. The $\mathrm{V}_{\mathrm{y} 0}$ to $V_{x 0}$ ratio was almost $1: 3(0.38 \pm 0.05)$, as $21.2 \pm 2.7 \%$ of $A_{\text {SVPP }}$ was lost at the instant of take-off. The average duration of the push-off at the take-off board was $0.120 \pm 0.006 \mathrm{~s} . V \times 0, V_{0}$ and ho were highly correlated with $S_{E F F}$, which was also moderately correlated with $D_{E F F}$.

Table 2. Results $(n=11)$ for the take-off parameters and the Pearson's correlation coefficients $(r)$ with the effective jump distance (SEFF).

\begin{tabular}{|c|c|c|c|c|}
\hline Parameter & mean & SD & $r$ & $p$ \\
\hline $\mathrm{TC}_{\mathrm{BO}}(\mathrm{s})$ & 0.121 & 0.006 & -.038 & .912 \\
\hline$V x_{0}(\mathrm{~m} / \mathrm{s})$ & 7.70 & 0.43 & .788 & $.004^{*}$ \\
\hline$\Delta V x_{0}(\mathrm{~m} / \mathrm{s})$ & -1.55 & 0.23 & .217 & .521 \\
\hline$V_{y_{0}}(\mathrm{~m} / \mathrm{s})$ & 2.90 & 0.23 & -.255 & .450 \\
\hline V VATIO & 0.38 & 0.05 & -.496 & .121 \\
\hline$V_{0}(\mathrm{~m} / \mathrm{s})$ & 8.24 & 0.37 & .849 & $.001^{*}$ \\
\hline$h_{0}(m)$ & 1.15 & 0.05 & -.780 & $.005^{\star}$ \\
\hline$\theta_{0}(\mathrm{deg})$ & 20.7 & 2.3 & -.498 & .119 \\
\hline$D_{\text {EFF }}(m)$ & 0.34 & 0.05 & .656 & $.028^{\star}$ \\
\hline$\varphi L_{T D}(\mathrm{deg})$ & 60.5 & 3.9 & -396 & .228 \\
\hline ӨkTD (deg) & 165.7 & 2.6 & .215 & .525 \\
\hline$\theta \mathrm{K}_{0}(\mathrm{deg})$ & 171.2 & 4.7 & .261 & .438 \\
\hline$\theta \mathrm{ksw}_{0}(\mathrm{deq})$ & 70.1 & 16.5 & .313 & .349 \\
\hline
\end{tabular}

Note: $T C_{B O}:$ push-off time at the take-off board; $V_{0}, V_{x_{0}}$ and $V_{y 0}$ : resultant, horizontal and vertical Body Centre of Mass take-off velocity; $\triangle V_{x_{0}}$ : horizontal velocity loss at the board; $V_{\text {RATIO: }}$ ratio of $V_{y_{0}}$ to $V_{x_{0}}$; $h_{0}$ : Body Centre of Mass take-off height; $\theta_{0}$ : take-off

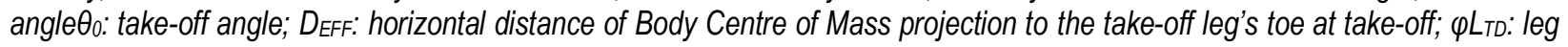
(ankle-hip long axis) angle to horizontal at touchdown to the board; $\theta k$ io and $\theta k 0$ : push-off leg knee angle at touchdown and takeoff from the board, respectively; $\theta k s w o:$ swing leg knee angle at take-off; *: $p<.05$.

V0, ho and $\theta_{0}$ significantly predicted $S_{E F F}\left(F_{3,7}=12.671, p=.003, R^{2}=.844\right.$; standard error of the estimate: .106). The individual predictors were examined further and indicated that $V_{0}(t=3.202, p=.015)$ was a significant predictor in the model (equation 6):

$$
S_{E F F}=0.16-0.44 \times h_{0}+0.75 \times V_{0}+0.06 \times \theta_{0}[6]
$$




\section{DISCUSSION}

The present analysis examined the late approach step variables and the take-off parameters under the perspective of inter-limb asymmetry and predictors of performance in elite female athletes during competition in a major indoor event. Results revealed that top European female long jumpers executed the approach utilising the "larger penultimate - shorter last step" technique, but with the existence of a significant inter-limb asymmetry in step frequency. In addition, performance (effective jump distance) was significantly related with height, angle and velocity of take-off, with the latter being a significant predictor.

The comparison with published data from a recent major indoor event (Tucker et al., 2019) reveals that the present findings are within reasonable agreement and in some cases identical, as for example the alteration of the step length among the last three steps (approximately 12\%). The result about the strong correlation of approach velocity with jumping distance is in agreement with the literature (Hay, 1993). It is custom jumpers to conclude the approach with maximum controlled velocity, which should be accomplished by attaining a large step frequency at the last steps (Hay, 1986). This was evident in the examined athletes, as step frequency was progressively increased till the third-to-last step. After that step, the "larger penultimate shorter last step" technique was utilised for the preparation of the take-off. This step pattern is commonly used in long jump (Hay and Miller, 1985; Hay and Nohara, 1990; Panoutsakopoulos and Kollias, 2007).

Along the attainment of the near maximum horizontal velocity during the late approach, long jumpers are required to negotiate the other constraint that occurs in the event, namely to hit accurately take-off board. As a result, step length regulation occurs at the last four or five steps of the approach (Hay, 1988; Hildebrandt and Cañal-Bruland, 2020; Theodorou et al., 2013). In the present study, approximately $73 \%$ of the total step length adjustments occurred at the last two steps, a percentage slightly larger to the one reported by Hay (1988). The importance of this factor should be interpreted in combination with the technical execution of the last two steps. It is suggested that the accuracy of foot placement on the board is increased when the approach is executed with small footfall variability (Makaruk et al., 2015). In the present study, toe-to-board accuracy was progressively decreased as the jumpers approached the board.

Compared to past research (Panoutsakopoulos et al., 2017), the flight to support time ratio at the penultimate step recorded at the present study was of similar magnitude as in male long jumpers. The temporal parameters of the last steps of the approach are suggested to characterise the effectiveness of the jumper's technique in the preparation for take-off (Hay and Nohara, 1990; Shimizu et al., 2011). This is evident at the last step, as jumpers maintain their speed, decreasing the step distance and flight time and acquire an optimum position for the following take-off (Hay, 1993). Aiding to the generation of vertical velocity are the placement of the extended take-off leg far ahead from the body, the low BCM height and a fast horizontal motion at the last step (Hay, 1986; Mendoza and Nixdorf, 2011). In a previous case report of a participant in the study (Panoutsakopoulos et al., 2020), at her best jump, the largest flight-to-contact time ratio was observed at the last step. This was accomplished with a toe-first contact, followed by a fast rotation over the support foot without an extensive flexion of the knee, resulting in a less energetic transition for planting the take-off foot at the board (Panoutsakopoulos et al., 2020). On the other hand, there is evidence in the literature that large extension movements of the support leg at the final step, along with a vertical torso, result in a disadvantageous take-off posture for female long jumpers (Murakami and Takahashi, 2016).

Increase in step frequency is the predominant action in which long jumpers increase late approach velocity (Hay, 1986). It has been found that a large number of female athletes rely on step frequency to increase approach velocity at the final stage of the approach (Exell et al., 2016). However, in the present study, a 
significant inter-limb asymmetry was observed for step frequency. In addition, the lateral differentiations of the step flight time in the final six steps resulted to a decreased step frequency for the steps commencing from the take-off leg, indicating an asymmetrical rhythmical execution of the final steps. Inter-limb asymmetry in step frequency is not uncommon in female jumpers (Exell et al., 2016). In general, inter-limb asymmetries can be attributed to the large musculoskeletal loading at the take-off (Linthorne et al., 2011), which might be related with the asymmetries that are observed in strength tests in long jumpers (Kobayashi et al., 2010). Nevertheless, past research revealed that asymmetries in step frequency were compensated with changes in step length, thus resulting in no significant asymmetry in step velocity (Theodorou et al., 2017).

It is suggested that an extended knee at the touchdown on the board are optimal for an effective take-off (Campos et al., 2013a). In the present study, the respective average knee angle and leg inclination were 166 deg and $61 \mathrm{deg}$. These angles can be considered to comprise a satisfactory body posture for the development of vertical velocity during the take-off phase (Lees et al., 1993; Muraki et al., 2008; Ramos et al., 2019). On the other hand, limited knowledge exists concerning the contribution of the swing leg (Hay, 1986). It is shown that initially enhances an undesired enhancement of forward rotation (Herzog, 1986). However, the powerful forward-upward motion of the swing leg is suggested to be a key factor (Panoutsakopoulos et al., 2010), since the elevation of the swing leg side of the pelvis assists the generation of vertical velocity with minimisation of the horizontal velocity loss (Sado et al., 2018). Thus, the contribution of motion of the swing leg has to be further investigated concerning the generation of angular momentum and its resulting effect in the technical execution of the flight phase.

The optimisation of women's long jump is suggested to be related with the vertical component of the take-off (Brüggemann and Nixdorf, 1985; Campos et al., 2013a; Lees et al., 1992), as the best female jumpers were able to better exploit the changes in the vertical component (Letzelter, 2011). In detail, the vertical take-off velocity, the BCM take-off height and the angle of take-off were found to be determining factors for better long jump performance (Panoutsakopoulos et al., 2007). It is believed that female long jumpers, because of the reduced power production ability compared to men (Miller et al., 1993), exchange the loss of energy deliberately by means of reducing the horizontal velocity for the gain in vertical velocity (Brüggemann and Nixdorf, 1985; Lees et al., 1992). In the previously published case study, the largest jump was accomplished with the highest recorded vertical velocity and height of take-off, thus indicating an effective conversion of horizontal to vertical energy (Panoutsakopoulos et al., 2020). About a fifth of the energy acquired in the approach by the analysed jumpers was exchanged to develop vertical velocity, which at the instant of takeoff was about a third of the horizontal velocity, as suggested in the literature (Brüggemann and Conrad, 1986). However, it is proposed that the loss of energy is not necessarily resulting in a decrease in jump performance, since the effectiveness of energy transformation is related with technique (Arampatzis and Brüggemann, 1999).

The relationship of the take-off parameters and the long jump performance revealed a strong, positive correlation between the effective distance and the approach speed. This is the most common observation in long jump studies (Brüggemann and Conrad, 1986; Hay, 1993). A strong, positive correlation was also revealed between the horizontal take-off velocity and the effective distance, confirming past findings in female long jumpers (Nemtsev et al., 2015). A strong, negative correlation was evident between the effective distance and the height of take-off. This finding can be interpreted as a fail to raise the body centre of mass and to acquire an upright position at take-off due to a poor arm swing and swing leg lift (Graham-Smith and Lees, 2005). A moderate, positive correlation was observed between the effective distance and the horizontal distance of the body centre of mass projection to the take-off point. This again can be addressed under the perspective of the proper body posture at the instant of take-off (Tidow, 1989). As for the prediction of the 
effective distance by the take-off parameters, resultant take-off velocity was proven to be a significant predictor as reported in previous studies (Brüggemann and Conrad, 1986). The angle of take-off, despite not significantly correlated with the effective distance, was included in the predictive equation. The inclusion of non-correlated parameters related to technique in the predictive equation of effective distance has shown that increases the coefficient of determination (Graham-Smith and Lees, 2005). This is proposed to be possibly due to fact that different athletes perform the long jump using different take-off techniques in a variety of levels regarding the effectiveness of the technical execution of the take-off motion (Nemtsev et al., 2018).

A number of limitations were noted in the study. Firstly, the limited number of the analysed athletes and the jumps attempted is a factor that is not allowing the generalisation of the current findings. Also, the regression analysis assumed a linear relation among the examined parameters. In addition, the landing parameters were not examined. This absence of this information deprives the thorough examination of the current indoor long jump technique of elite women in terms of the angular momentum gained during take-off, its effect on the landing distance and the techniques used in the preparation for landing. Finally, the analysis of only six steps of the late approach did not allow providing data about the onset of the step length regulation. Future research on the topic should investigate factors such as the reliance of speed development on the step parameters (length and frequency) and the effect of the possible inter-limb asymmetries occurring in the approach on the energy transformation and, eventually, on the take-off parameters.

\section{CONCLUSIONS}

The biomechanical analysis of the 2017 European Athletics Indoor Championships showed that the essential factors in the women's long jump were the approach velocity, the velocity, angle and height of take-off, as well as the horizontal distance from the BCM to the toe of the take-off leg at the instant of take-off. In addition, significant inter-limb asymmetry was observed for the step frequency and the flight time of the final steps. Therefore, coaches and practitioners aiming for the improvement in female long jumpers should give the necessary emphasis in the accuracy of foot placements, the regulation of inter-limb asymmetries regarding the temporal parameters and the efficient transformation of the horizontal to vertical take-off velocity by acquiring the proper take-off posture with high body centre of mass height and distance from the take-off point.

\section{ACKNOWLEDGEMENTS}

Appreciation is extended to the European Athletics Association and the Belgrade 2017 Organizing Committee for the permission and assistance to record the event.

\section{REFERENCES}

Akl, A. R. (2014). Biomechanical study to assess the variations between male and female in long jump. Sport Sci Pract Asp, 11(1), 33-36.

Arampatzis, A., \& Brüggemann, G.-P. (1999). Mechanical energetic processes in long jump and their effect on jumping performance. New Stud Athl, 14(4), 37-44.

Brüggemann, G. P., \& Conrad, T. (1986). Long jump. In: Susanka, P., Brüggemann, G. P., Tsarouhas, E. (Eds.), Biomechanical Research in Athletics - 1st World Junior Championships, Athens 1986 (pp. 89-119, in Greek). Athens: S.E.G.A.S. - E.K.A.E. 
Bruggemann, P., \& Nixdorf, E. (1985). Sex-specific differences in the technical and motor apparatus of the jumps. In: Women's Track and Field Athletics (pp. 219-230). Darmstadt, Germany: Deutscher Leichtathletik-Verband.

Campos, J., Gámez, J., Encarnación, A., Gutiérrez-Dávila, M., \& Rojas, J. (2013a). Three dimensional kinematic analysis of the long jump at the 2008 IAAF World Indoor Championships in Athletics. New Stud Athl, 28(3/4), 115-131.

Campos, J., Gámez, J., Encarnación, A., Gutiérrez-Dávila, M., Rojas, J., \& Wallace, E. S. (2013b). Threedimensional kinematics during the take-off phase in competitive long jumping. Int J Sports Sci Coaching, 8(2), 395-406. https://doi.org/10.1260/1747-9541.8.2.395

Cohen, J. (1988). Statistical power analysis for the behavioral sciences (2nd ed.). Hillsdale, N.J.: Lawrence Erlbaum Associates Publishers.

Dempster, W. T. (1955). Space requirements of the seated operator. WADCTR (55-59). Dayton, Ohio, USA: Wright Patterson Air Force Base.

Exell, T., Theodorou, A., \& Panoutsakopoulos, V. (2016). Step characteristics during long jump approach: Reliance and asymmetry considerations. In: Ae, M., Enomoto, Y., Fujii, N., Takagi, H. (Editors), Proceedings of the XXXIV International Symposium on Biomechanics in Sports (pp. 581-584). Tsukuba, Japan: International Society of Biomechanics in Sports.

Gervais, P., Bedingfield, E. W., Wronko, C., Kollias, I., Marchiori, G., Kuntz, J., Way, N., \& Kuiper, D. (1989). Kinematic measurement from panned cinematography. Can J Sports Sci, 14(2), 107-111.

Graham-Smith, P., \& Lees, A. (2005). A three-dimensional kinematic analysis of the long jump take-off. J Sports Sci, 23(9), 891-903. https://doi.org/10.1080/02640410400022169

Hay, J. G. (1986). The biomechanics of the long jump. Exer Sport Sci Rev, 14(1), 401-446. https://doi.org/10.1249/00003677-198600140-00017

Hay, J. G. (1988). Approach strategies in the long jump. Int J Sport Biomech, 4(2), 114-129. https://doi.org/10.1123/ijsb.4.2.114

Hay, J. G. (1993). Citius, altius, longius (faster, higher, longer): the biomechanics of jumping for distance. J Biomech, 26(Suppl. 1), 7-21. https://doi.org/10.1016/0021-9290(93)90076-Q

Hay J. G., \& Miller, J. A. (1985). Techniques used in the transition from approach to takeoff in the long jump. Int J Sport Biomech, 1(2), 174-184. https://doi.org/10.1123/ijsb.1.2.174

Hay, J. G., \& Nohara, H. (1990). Techniques used by elite long jumpers in preparation for takeoff. J Biomech, 23(3), 229-239. https://doi.org/10.1016/0021-9290(90)90014-T

Herzog, W. (1986). Maintenance of body orientation in the flight phase of long jumping. Med Sci Sports Exerc, 18(2), 231-241. https://doi.org/10.1249/00005768-198604000-00014

Hildebrandt, A., \& Cañal-Bruland, R. (2020). Is gait-based visual regulation identical to gaze-based visual regulation in inexperienced athletes' long jump run-ups? Hum Mov Sci, 73, 102681. https://doi.org/10.1016/j.humov.2020.102681

Kobayashi, Y., Kubo, J., Matsuo, A., Matsubayashi, T., Kobayashi, K., \& Ishii, N. (2010). Bilateral asymmetry in joint torque during squat exercise performed by long jumpers. J Strength Cond Res, 24(10), 2826-2830. https://doi.org/10.1519/JSC.0b013e3181c64387

Lees, A., Derby, D., \& Fowler, N. (1992). Sex differences in the jump touchdown and take-off characteristics of the long jump. J Sports Sci, 10(6), 588-589.

Lees, A., Fowler, N., \& Derby, D. (1993). A biomechanical analysis of the last stride, touch-down and take-off characteristics of the women's long jump. J Sports Sci, 11(4), 303-314. https://doi.org/10.1080/02640419308730000

Letzelter, S. (2011). The importance of horizontal and vertical take-off velocity for elite female long jumpers. New Stud Athl, 26(3/4), 73-84. 
Linthorne, N. P. (2008). Biomechanics of the long jump. In: Y. Hong \& R. Bartlett (Eds.), Routledge handbook of biomechanics and human movement science (pp. 340-353). London, UK: Routledge. https://doi.org/10.4324/9780203889688

Linthorne, N. P., Baker, C., Douglas, M. M., Hill, G. A., \& Webster, R. G. (2011). Take-off forces and impulses in the long jump. Port J Sport Sci, 11(Suppl. 3), 33-36.

Luhtanen, P., \& Komi, P. V. (1979). Mechanical power and segmental contribution to force impulses in long jump take-off. Eur J Appl Physiol Occup Physiol, 41(4), 267-274. https://doi.org/10.1007/BF00429743

Makaruk, H., Starzak, M., \& Sadowski, J. (2015). Does step length adjustment determine take-off accuracy and approach run velocity in long and triple jumps? Hum Mov, 16(3), 124-129. https://doi.org/10.1515/humo-2015-0038

Mendoza, L., \& Nixdorf, E. (2011). Biomechanical analysis of the horizontal jumping events at the 2009 IAAF World Championships in Athletics. New Stud Athl, 26(3/4), 25-60.

Miller, A. E., MacDougall, J. D., Tarnopolsky, M. A., \& Sale, D. G. (1993). Gender differences in strength and muscle fiber characteristics. Eur J Appl Physiol, 66(3), 254-262. https://doi.org/10.1007/BF00235103

Murakami, Y., \& Takahashi, K. (2016). Research on gender differences of preparative motion for takeoff in the long jump. In: M. Ae, Y. Enomoto, N. Fujii, \& H. Takagi (Eds.), Proceedings of the 34th International Conference of Biomechanics in Sports (pp. 807-810). Tsukuba, Japan: International Society of Biomechanics in Sports.

Muraki, Y., Ae, M., Koyama, H., \& Yokozawa, T. (2008). Joint torque and power of the takeoff leg in the long jump. Int J Sport Health Sci, 6, 21-32. https://doi.org/10.5432/ijshs.6.21

Nemtsev, O., Nemtseva, N., Bguashev, A., Elipkhanov, S., \& Grekalova, I. (2016). Gender differences in takeoff techniques of non-elite Russian long jumpers. J Hum Sport Exer, 11(4), 444-454. https://doi.org/10.14198/ihse.2016.114.05

Nemtsev, O. B., Nemtseva, N. A., Sukhanov, S. M., Lytkin, A. V., \& Parfenova, S. O. (2015). Technical features of take-off of female long jumpers of different skill levels. Teoriya i Praktika Fizicheskoy Kultury, 1, 36-38.

Nemtsev, O., Pevneva, M., Polyanskiy, A., Dukalskaya, A., \& Doludenko, E. (2018). Qualification differences in interrelationships of takeoff variables of male long jumpers. J Phys Ed Sport, 18(Suppl. 1), 485-489.

Panoutsakopoulos, V., \& Kollias, I. (2007). Biomechanical analysis of sub-elite performers in the women's long jump. New Stud Athl, 22(4), 19-28.

Panoutsakopoulos, V., \& Kollias, I. A. (2009). Biomechanical analysis of the last strides, the touchdown and the takeoff of top Greek male and female long jumpers. Hellenic J Phys Ed Sport Sci, 29(2), 200-218.

Panoutsakopoulos, V., Papaiakovou, G. I., Katsikas, F. S., \& Kollias, I. A. (2010). 3D Biomechanical analysis of the preparation of the long jump take-off. New Stud Athl, 25(1), 55-68.

Panoutsakopoulos, V., Tampakis, K., Papaiakovou, G., \& Kollias, I. A. (2007). Factor analysis of biomechanical parameters which define performance in the long jump. Exer Soc, 46, 121-124.

Panoutsakopoulos, V., Theodorou, A. S., Kotzamanidou, M. C., \& Kollias, I. A. (2020). Biomechanical analysis of the 2017 European indoor champion in the women's long jump: case report. Exer Qual Life, 12(1), 5-13. https://doi.org/10.31382/eqol.200601

Panoutsakopoulos, V., Theodorou, A. S., \& Papaiakovou, G. I. (2017). Gender differences in the preparation for take-off in elite long jumpers. Acta Gymnica, 47(2), 84-91. https://doi.org/10.5507/ag.2017.011 
Pueo, B. (2016). High speed cameras for motion analysis in sports science. J Hum Sport Exer, 11(1), 53-73. https://doi.org/10.14198/jhse.2016.111.05

Ramos, C. D., Ramey, M., Wilcox, R. R., \& McNitt-Gray, J. L. (2019). Generation of linear impulse during the takeoff of the long jump. J Appl Biomech, 35(1), 52-60. https://doi.org/10.1123/jab.2017-0249

Sado, N., Yoshioka S., \& Fukashiro, S. (2018). Effect of segmental rotations on vertical and horizontal energies during take-off of a long jump. ISBS Proceedings Archive, 36(1), 806-810.

Shimizu, Y., Ae, M., \& Koyama, H. (2011). A biomechanical study of the takeoff preparation and the takeoff motions in elite male long jumpers. Port J Sport Sci, 11(Suppl. 2), 381-383.

Theodorou, A. S., loakimidou, E., Kouris, P., Panoutsakopoulos, V., \& Smpokos, E. (2013). Colour contrast and regulation of the long jump approach run. J Hum Sport Exer, 8(Proc. 3), S681-S687. https://doi.org/10.4100/jhse.2013.8.Proc3.14

Theodorou, A. S., Panoutsakopoulos, V., Exell, T. A., Argeitaki, P., Paradisis, G. P., \& Smirniotou, A. (2017). Step characteristic interaction and asymmetry during the approach phase in long jump. J Sports Sci, 35(4), 346-354. https://doi.org/10.1080/02640414.2016.1164884

Tidow, G. (1989). Model technique analysis sheet for the horizontal jumps. Part I-The long jump. New Stud Athl, 3(3), 47-62.

Tucker, C. B., Bissas, A. \& Merlino, S. (2019). Biomechanical Report for the IAAF World Indoor Championships 2018: Long Jump Women. Birmingham, UK: International Association of Athletics Federations.

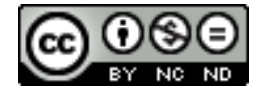

This work is licensed under a Attribution-NonCommercial-NoDerivatives 4.0 International (CC BY-NC-ND 4.0). 